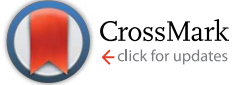

Cite this: RSC Adv., 2016, 6, 30425
Received 6th February 2016

Accepted 16th March 2016

DOI: 10.1039/c6ra03501a

www.rsc.org/advances

\section{ZnO/ZnS heterostructures for hydrogen production by photoelectrochemical water splitting $\dagger$}

\author{
R. Sánchez-Tovar, R. M. Fernández-Domene, M. T. Montañés, A. Sanz-Marco \\ and J. Garcia-Antón*
}

\begin{abstract}
This work studies the photoelectrochemical behavior of novel $\mathrm{ZnO} / \mathrm{ZnS}$ heterostructures obtained by means of anodization in water and glycerol/water $/ \mathrm{NH}_{4} \mathrm{~F}$ electrolytes with different $\mathrm{Na}_{2} \mathrm{~S}$ additions under controlled hydrodynamic conditions. For this purpose different techniques such as Field Emission Scanning Electronic Microscopy (FE-SEM) with EDX, Raman spectroscopy and photoelectrochemical water splitting tests under standard AM 1.5 conditions have been carried out. The obtained results showed that the hydrodynamic conditions promoted an ordered nanotubular morphology which facilitates electron-hole separation and consequently, the photoelectrochemical activity for water splitting is enhanced. Additionally, the effect of glycerol in the anodization solutions seems to be beneficial for increasing the dark current photostability.
\end{abstract}

\section{Introduction}

Nowadays, the use of titanium dioxide $\left(\mathrm{TiO}_{2}\right)$ as a photocatalyst has gained special attention due to its outstanding properties. $^{1-3}$ Zinc oxide $(\mathrm{ZnO})$ is also an n-type-wide band gap semiconductor $(3.37 \mathrm{eV})$ with similar characteristics as $\mathrm{TiO}_{2}$ but with the advantage that $\mathrm{ZnO}$ possesses a higher electron mobility (from 10 to 100 times higher in comparison to $\mathrm{TiO}_{2}$ ); i.e. a large conductivity which makes $\mathrm{ZnO}$ a very suitable and promising substitute for $\mathrm{TiO}_{2} \cdot{ }^{4,5}$ Nevertheless, the photocatalytic efficiency of $\mathrm{ZnO}$ is considerably low due to the rapid recombination of the photogenerated electron-hole pairs. In order to overcome this issue, recent studies ${ }^{6,7}$ have proposed the use of hybrid semiconductors systems which might promote the separation of electron-hole pairs and retain reduction and oxidation reactions at two different sites. ${ }^{8}$ According to this, the recombination of photogenerated electron-hole pairs may be suppressed and consequently, the photocatalytic efficiency would be increased. Due to its importance, several works have been related to this topic; that is the formation of different heterostructures containing $\mathrm{ZnO}$, such as: $\mathrm{ZnO} / \mathrm{ZnS}$, ${ }^{6,7,9} \mathrm{SnO}_{2} / \mathrm{ZnO},{ }^{10}$ $\mathrm{ZnO} / \mathrm{In}_{2} \mathrm{O}_{3}{ }^{11} \mathrm{ZnO} / \mathrm{Bi}_{2} \mathrm{O}_{3}$ (ref. 12 ) and $\mathrm{ZnO} / \mathrm{ZnIn}_{2} \mathrm{~S}_{4} \cdot{ }^{13}$

Among them, this study is focused on $\mathrm{ZnO} / \mathrm{ZnS}$ heterostructures due to the good photocatalytic behavior of $\mathrm{ZnS} ;^{7}$ i.e. its

Ingeniería Electroquímica y Corrosión (IEC), Departamento de Ingeniería Química y Nuclear, ETSI Industriales, Universitat Politècnica de València, Camino de Vera $\mathrm{s} / \mathrm{n}$, 46022 Valencia, Spain . E-mail: jgarciaa@iqn.upv.es; Fax: +34-96-387 76 39; Tel: $+34-96-3877632$

† Electronic supplementary information (ESI) available. See DOI: 10.1039/c6ra03501a rapid electron-hole pairs generation together with a higher negative reduction potential of the excited electron. In fact, $\mathrm{ZnO} /$ ZnS heterostructures could reduce the recombination rate of the charge carriers owing to their separated band gaps. That is, the conduction band of $\mathrm{ZnS}$ lies on a more negative potential than that of $\mathrm{ZnO}$, whereas the valence band of $\mathrm{ZnO}$ is more positive than that of $\mathrm{ZnS}^{.14}$ Under solar-simulated light, the photogenerated electrons from the conduction band of ZnS nanoparticles could be transferred to that of the $\mathrm{ZnO}$, and holes on the valence band of $\mathrm{ZnO}$ can be transferred to that of the $\mathrm{ZnS}$.

Usually, $\mathrm{ZnO} / \mathrm{ZnS}$ heterostructures with different morphologies, such as nanowires, ${ }^{6,9}$ nanorings ${ }^{15}$ and other different nanostructures, ${ }^{7}$ have been synthetized by means of solutionchemical processes. These chemical processes generate a high number of impurities in the final products. A very good alternative to form nanostructures is anodization of zinc. This technique makes possible to grow the nanostructures directly on the metal substrate (back contact), so they can be used directly as photoanodes, thus avoiding compaction or sintering of nanoparticles on the metallic substrate. ${ }^{16}$ Whether the correct electrolyte is selected, $\mathrm{ZnO} / \mathrm{ZnS}$ heterostructures can be formed on zinc by electrochemical anodization. There is scarce literature that evaluates the photoelectrochemical behavior of $\mathrm{ZnO} / \mathrm{ZnS}$ nanostructures obtained by anodization. ${ }^{17}$ Additionally, these studies are carried out anodizing under static conditions.

In previous researches, we found that the geometry of the $\mathrm{TiO}_{2}$ nanostructures could be modified by stirring the titanium electrode during anodization. ${ }^{18}$ In the present work, $\mathrm{ZnO} / \mathrm{ZnS}$ heterostructures have been synthetized by electrochemical anodization under stagnant and stirring conditions in $\mathrm{Na}_{2} \mathrm{~S}$ / 
$\mathrm{NH}_{4} \mathrm{~F}$ electrolytes. The effect of $\mathrm{Na}_{2} \mathrm{~S}$ concentration as well as the influence of glycerol in the electrolyte was also evaluated. The morphology of the heterostructures was characterized using field emission scanning electron microscopy (FE-SEM) with EDX and their crystallinity with Raman spectroscopy. The final purpose of this work is to study the photocatalytic behavior of the formed $\mathrm{ZnO} / \mathrm{ZnS}$ heterostructures for hydrogen production by photoelectrochemical water splitting.

\section{Experimental procedure}

Anodization under hydrodynamic conditions was performed in a 2-electrode electrochemical cell with a rotating electrode configuration. The anode was a Teflon coated zinc rod $(8 \mathrm{~mm}$ diameter, $99.999 \%$ purity) in a rotating electrode setup. For all experiments, $0.5 \mathrm{~cm}^{2}$ of the sample was exposed to the electrolyte. Prior to the anodization process, the zinc rod surface was abraded with 500 to 4000 silicon carbide (SiC) papers, in order to obtain a mirror finish. After this, the sample was sonicated in ethanol for $2 \mathrm{~min}$ and dried in a $\mathrm{N}_{2}$ stream. For anodization a voltage source was used, where the zinc rod served as working electrode and a platinum foil $\left(1 \mathrm{~cm}^{2}\right)$ acted as counter electrode. Four different electrolytes were used for these experiments, which consisted of a solution with $0.025 \mathrm{M}$ $\mathrm{NH}_{4} \mathrm{~F}$ and $0.06 \mathrm{M}$ or $0.2 \mathrm{M} \mathrm{Na} \mathrm{N}_{2} \mathrm{~S}$ in water or glycerol/water (60 : $40 \mathrm{vol} \%$ ) media. All the samples were anodized at $30 \mathrm{~V}$ by increasing the potential from zero to the desired value at a rate of $200 \mathrm{mV} \mathrm{s}^{-1}$, followed by keeping the end potential for 1 hour at two different rotation speeds: 0 and $2000 \mathrm{rpm}$, respectively. Current densities vs. time were registered during anodization.

After each test, a field-emission scanning electron microscope (FE-SEM) was used for morphological characterization of the obtained samples. For photoelectrochemical water splitting measurements, the nanostructures were annealed in a furnace at $375^{\circ} \mathrm{C}$ (heating at a rate of $30{ }^{\circ} \mathrm{C} \mathrm{s}^{-1}$ ) in argon atmosphere for 4 hours. The materials were also examined by Raman spectroscopy ("Witec Raman microscope") after the heat treatment, in order to evaluate their crystalline structure. For these measurements the samples were illuminated with a $632 \mathrm{~nm}$ neon laser using $420 \mu \mathrm{W}$.

For the photoelectrochemical water splitting tests, a threeelectrode configuration was used. The area of the nanostructures (working electrode) exposed to the test solution was $0.13 \mathrm{~cm}^{2}$. A saturated $\mathrm{Ag} / \mathrm{AgCl}(3 \mathrm{M} \mathrm{KCl})$ electrode was used as reference electrode, and a platinum tip was the counter electrode. These measurements were carried out under simulated sunlight condition AM $1.5\left(100 \mathrm{~mW} \mathrm{~cm}^{2}\right)$ in several electrolytes in other to find the most appropriate for characterizing the formed nanostructures. In this way, the nanostructures were evaluated in $1 \mathrm{M} \mathrm{NaOH}, 0.1 \mathrm{M} \mathrm{Na}_{2} \mathrm{SO}_{4}$ and finally, in the unique solutions that prevents $\mathrm{ZnO} / \mathrm{ZnS}$ dissolution, i.e. a mixture of $0.24 \mathrm{M} \mathrm{Na}_{2} \mathrm{~S}$ and $0.35 \mathrm{M} \mathrm{Na}_{2} \mathrm{SO}_{3}$, which was previously degasified using nitrogen.

Photocurrent $v s$. voltage characteristics were recorded by scanning the potential from $-1.0 \mathrm{~V}_{\mathrm{Ag} / \mathrm{AgCl}}$ to $1.2 \mathrm{~V}_{\mathrm{Ag} / \mathrm{AgCl}}$ with a scan rate of $2 \mathrm{mV} \mathrm{s}^{-1}$. Photocurrent transients as a function of the applied potential were recorded by chopped light irradiation (60 $\mathrm{s}$ in the dark and $20 \mathrm{~s}$ in the light).

\section{Results and discussion}

\subsection{Raman spectroscopy characterization}

Fig. 1 and 2 show the Raman spectra of the as-anodized and annealed $\mathrm{ZnO} / \mathrm{ZnS}$ nano-heterostructures formed in the different electrolytes, respectively. According to Fig. 1a and b, the Raman spectra of the as-anodized samples show the same grade of crystallinity, since several $\mathrm{ZnO}$ and $\mathrm{ZnS}$ characteristic peaks could be elucidated. In both water and glycerol/water electrolytes, peaks centered roughly at 333 and $438 \mathrm{~cm}^{-1}$ can be discerned, which are related to second order Raman scattering ( $E_{2}$ (high) $-E_{2}$ (low)) and $E_{2}$ (high) of $\mathrm{ZnO}$, respectively. ${ }^{\mathbf{1 9 , 2 0}}$ The former is originated from multiple-phonon scattering associated with $\mathrm{Zn}-\mathrm{O}$ vibration ${ }^{21}$ and the latter to oxygen atoms. ${ }^{22}$ Particularly, $E_{2}$ (low) is associated with the vibration of the heavy $\mathrm{Zn}$ sublattice, while $E_{2}$ (high) mode corresponds to band characteristic of wurtzite phase. ${ }^{23}$ Additionally, two narrow bands are presented at $\sim 203 \mathrm{~cm}^{-1}, \sim 410 \mathrm{~cm}^{-1}$ and $\sim 574 \mathrm{~cm}^{-1}$ which corresponds to the Raman scattering 2TA/ $2 E_{2}$ (low), $E_{1}$ (TO) and $A_{1}(\mathrm{LO})$ respectively. ${ }^{19,24}$ On the other hand, the TO phonon peak of ZnS was observed at $\sim 270 \mathrm{~cm}^{-1}$ and the LO mode at $\sim 350 \mathrm{~cm}^{-1}$, which correspond to $\mathrm{ZnS}^{7,24,25}$ Regarding Fig. 1b that shows the Raman spectra for the samples anodized in glycerol/water electrolytes, an additional peak can be appreciated at roughly $1100 \mathrm{~cm}^{-1}$ (see the highlighted box in Fig. 1b). In the region of $900-1600 \mathrm{~cm}^{-1}$ the vibrational modes originated from $\mathrm{CCO}, \mathrm{CH}_{2}$ and $\mathrm{COH}$ deformations of primary alcohols are found. ${ }^{26}$ In particular, the band at $\sim 1100 \mathrm{~cm}^{-1}$ is associated with the $\mathrm{C}-\mathrm{OH}$ mode ${ }^{27}$ due to the glycerol content of the electrolyte. Therefore, the Raman spectra of the as-anodized samples support $\mathrm{ZnO}$ and $\mathrm{ZnS}$ contents. Besides, EDX analysis of the anodized nanostructures reveal the presence of $\mathrm{Zn}, \mathrm{O}$ and $\mathrm{S}$ in the atomic concentration of $42.90 \pm 0.69 \%, 50.72 \pm 2.36 \%$ and $6.48 \pm 1.10 \%$, respectively (Fig. 1c shows an example of the EDX spectrum of the sample anodized in $0.2 \mathrm{M} \mathrm{Na}_{2} \mathrm{~S}$ and 0.0125 $\mathrm{M} \mathrm{NH} \mathrm{NH}_{4}$ at $2000 \mathrm{rpm}$ in water). In addition to the optical phonon modes shown in Fig. 1a and b, a broad background response is clearly seen in the Raman scattering of the asanodized samples and this effect is stronger for the nanostructures annealed at $375{ }^{\circ} \mathrm{C}$ during 4 hours (Fig. 2). This response is related to the photoluminescence (PL) occasioned from $\mathrm{ZnS}$, which is more marked after annealing, due to the high amount of ZnS after the heat treatment. In fact, samples after annealing presented a more yellow-brownish colour owing to their high sulphur content. ${ }^{6}$

Several authors observed this PL response in zinc-based nanostructures ( $\mathrm{ZnO}, \mathrm{ZnS}$ or heterostructures of them) at different wavelength, attributing the PL to a broad defect band emission, such as oxygen vacancies, surface defects and so on. ${ }^{\mathbf{6} 28-31}$ Additionally, PL responses from $\mathrm{ZnS}$ nanostructures were reported in the spectral region from red to green (700-520 $\mathrm{nm}) .{ }^{32,33}$ In particular, Kim ${ }^{34}$ obtained a broad PL response from $\mathrm{ZnS}$ nanowires excited at $1.96 \mathrm{eV}$ and they related this PL response to defects in the ZnS nanostructures. In this study, the 
a)

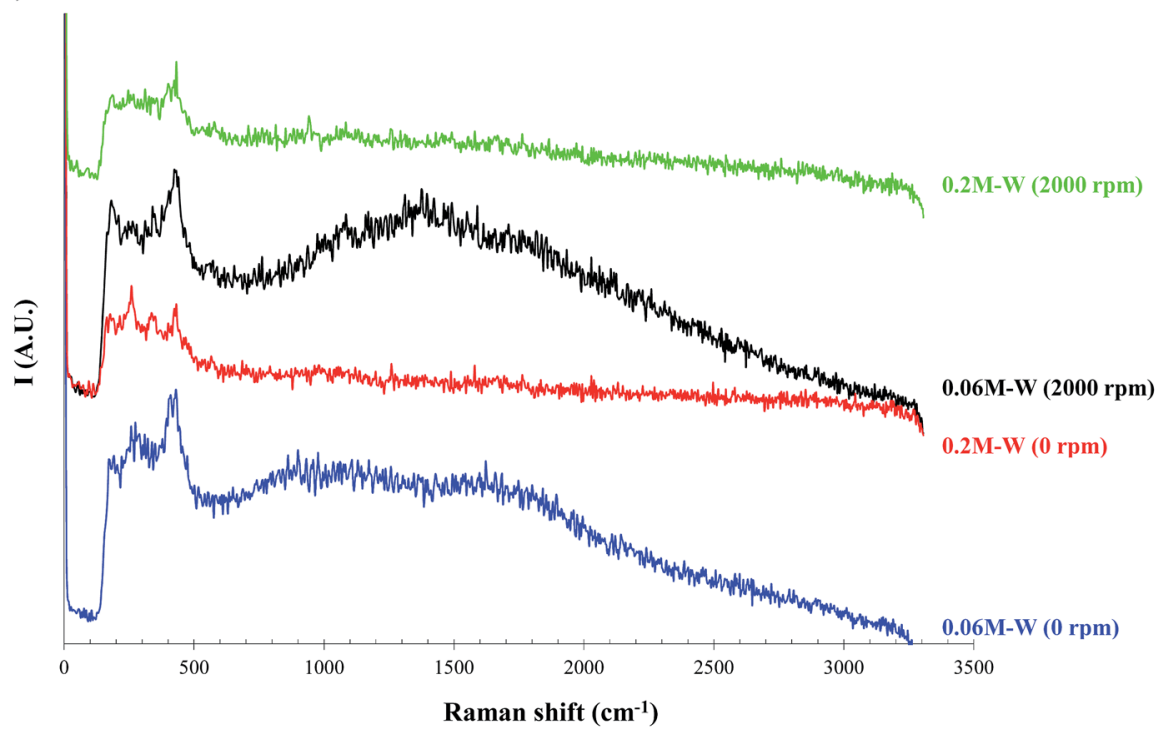

b)

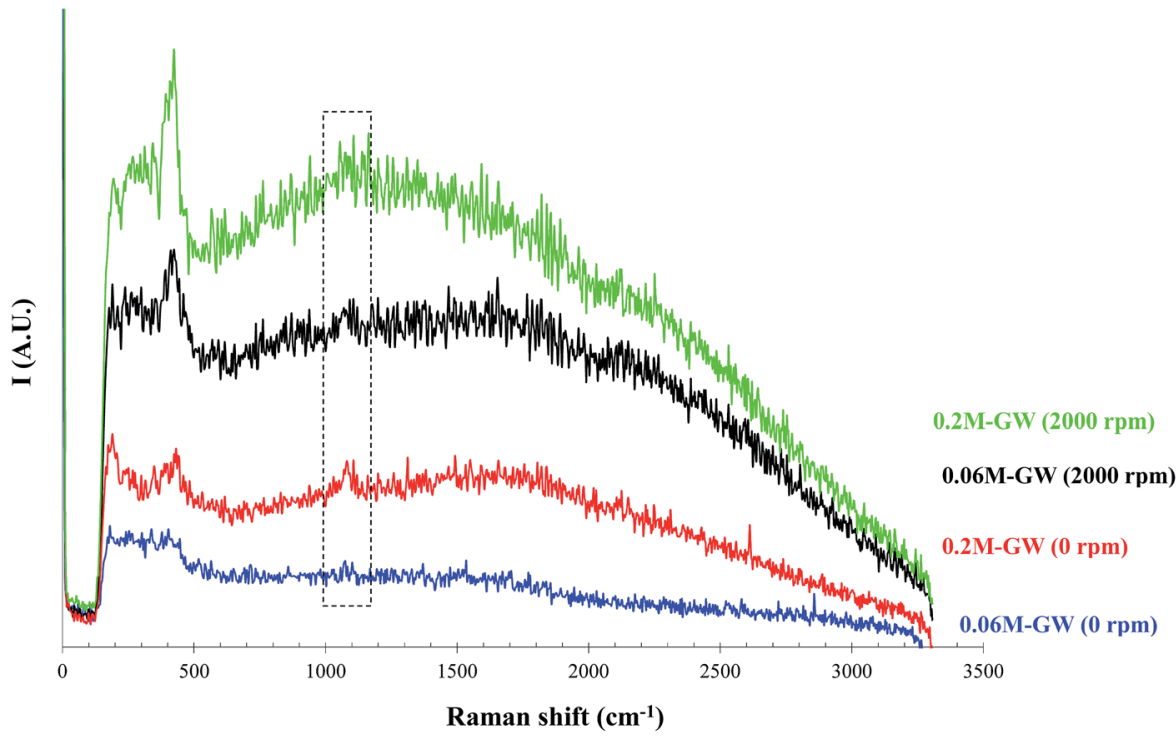

c)

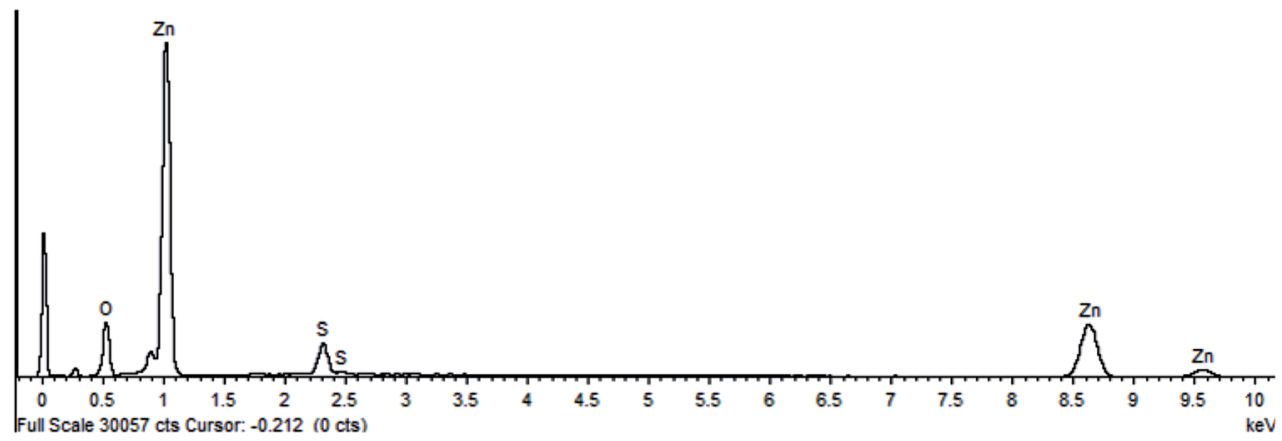

Fig. 1 Raman spectra of as-anodized $\mathrm{ZnO} / \mathrm{ZnS}$ nanostructures at 0 and $2000 \mathrm{rpm}$ in 0.2 and $0.06 \mathrm{M} \mathrm{Na}_{2} \mathrm{~S}+0.0125 \mathrm{M} \mathrm{NH}_{4} \mathrm{~F} \mathrm{water:} \mathrm{W} \mathrm{(a)} \mathrm{and}$ glycerol/water: GW (b) electrolytes. EDX analysis of the $\mathrm{ZnO} / \mathrm{ZnS}$ nanostructure anodized at $2000 \mathrm{rpm}$ in $0.2 \mathrm{M} \mathrm{Na}_{2} \mathrm{~S}-0.0125 \mathrm{M} \mathrm{NH}_{4} \mathrm{~F}$ water electrolyte (c). 

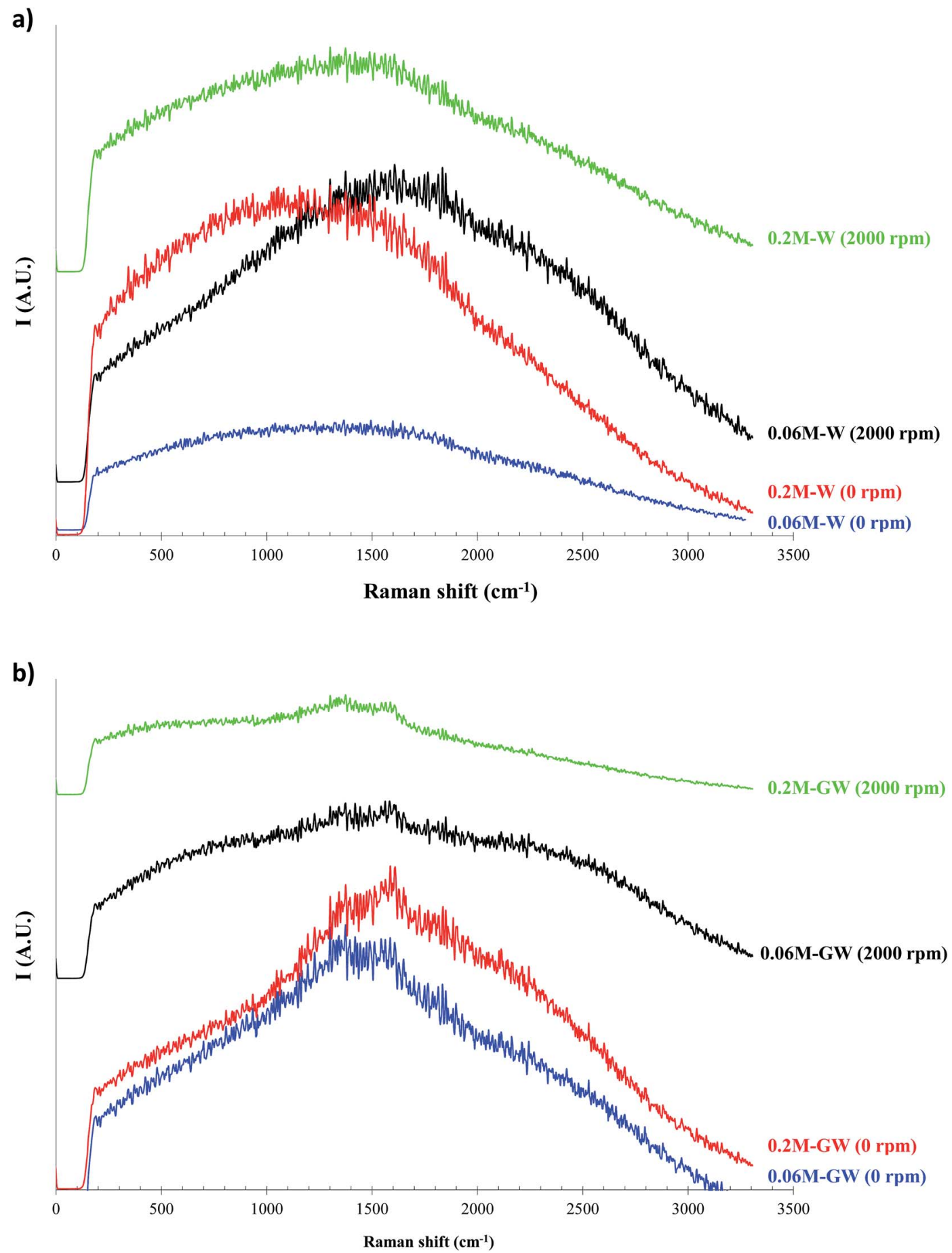

Fig. 2 Raman spectra of annealed $\mathrm{ZnO} / \mathrm{ZnS}$ nanostructures at 0 and $2000 \mathrm{rpm}$ in 0.2 and $0.06 \mathrm{M} \mathrm{Na}_{2} \mathrm{~S}-0.0125 \mathrm{M} \mathrm{NH}_{4} \mathrm{~F}$ water: W (a) and glycerol/water: GW (b) electrolytes.

Raman measurements were performed using a $\lambda=632 \mathrm{~nm}$, which corresponds to $1.96 \mathrm{eV}$ according to eqn (1).

$$
E=\frac{h c}{\lambda}
$$

where $E$ is the energy in $\mathrm{eV}, h$ is the Plank's constant $(6.626 \times$ $\left.10^{-34} \mathrm{~J} \mathrm{~s}=4.1356 \times 10^{-15} \mathrm{eV} \mathrm{s}\right), c$ is the speed of light $\left(3 \times 10^{8}\right.$ $\left.\mathrm{m} \mathrm{s}^{-1}\right)$ and $\lambda$ is the wavelength $\left(632 \times 10^{-9} \mathrm{~m}\right)$.
Zhang $^{30}$ observed that green, orange and red emissions appeared for $\mathrm{ZnO}$ nanostructures after annealing. They related the green emission with oxygen vacancies and orange $(\lambda=632$ $\mathrm{nm}$ ) and red emission to surface state defects. ${ }^{35}$ The strong PL shown in Fig. 2 originated by the defects of $\mathrm{ZnO}$ and $\mathrm{ZnS}$ hinders the rest of the characteristic peaks of $\mathrm{ZnO}$ and $\mathrm{ZnS}$. Only some weak bands at $\sim 1300-1600 \mathrm{~cm}^{-1}$ might be appreciated in the Raman spectra of the nanostructures formed in 
glycerol/water electrolytes, due to the residual carbon content. ${ }^{27,36}$

\subsection{Morphological characterization with FE-SEM images}

Fig. 3 shows the FE-SEM images of the $\mathrm{ZnO} / \mathrm{ZnS}$ nanostructures. It was established that the anodization of zinc in aqueous electrolytes containing both sulfide and fluoride develops a top compact layer and an underneath nanostructure. ${ }^{17}$ The former mainly consists of $\mathrm{ZnS}$ and the later of $\mathrm{ZnO}$. In the experiments carried out in this work, after anodization under static conditions a very rough white precipitate was formed on the surface of the anodized samples (Fig. S1a and b, S2a and b, S3a and $\mathrm{b}$ and $\mathrm{S} 4 \mathrm{a}$ and $\mathrm{b} \dagger)$. On the one hand, the effect of flowing conditions (Fig. S1d and e, S2d and e, S3d and e and S4d and e $\dagger$ ) is to transform this coarse precipitate into a very smooth anodized surface. Concerning the nanostructures formed in the electrolytes with the lower $\mathrm{Na}_{2} \mathrm{~S}$ concentration $(0.06 \mathrm{M})$, it is important to point out that the morphology obtained after
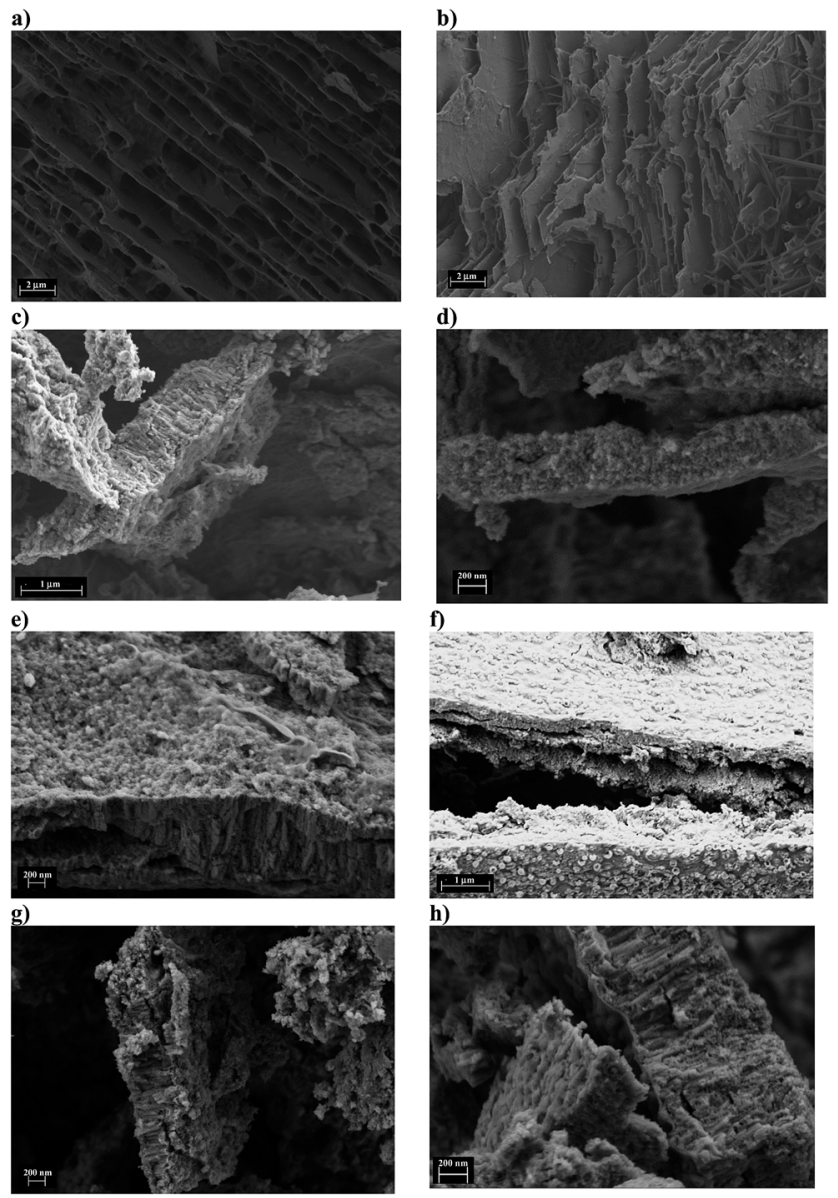

Fig. 3 FE-SEM images of the $\mathrm{ZnO} / \mathrm{ZnS}$ heterostructures anodized under static conditions in $0.06 \mathrm{M} \mathrm{Na}_{2} \mathrm{~S}+0.0125 \mathrm{M}$ water (a) and glycerol/water electrolytes (b), respectively; under dynamic conditions in $0.06 \mathrm{M} \mathrm{Na}_{2} \mathrm{~S}+0.0125 \mathrm{M}$ water (c) and glycerol/water electrolytes (d), respectively; under static conditions in $0.2 \mathrm{M} \mathrm{Na}_{2} \mathrm{~S}+0.0125 \mathrm{M}$ water (e) and glycerol/water electrolytes (f), respectively; under dynamic conditions in $0.2 \mathrm{M} \mathrm{Na}_{2} \mathrm{~S}+0.0125 \mathrm{M}$ water $(\mathrm{g})$ and glycerol/ water electrolytes (h), respectively. anodization under static conditions is typical of nanosheets which appear underneath the initiation layer (Fig. 3a and b). On the other hand, the initiation layer is covered with star-like shapes which give this layer a high roughness and surface/ area. This morphology can be clearly observed in the samples formed in aqueous electrolytes (Fig. S1b and $c^{\dagger}$ ). On the other hand, the nanosheets presented underneath the initiation layer are connected one parallel to another with a feature size of approximately 50 and $75 \mathrm{~nm}$ and a distance of roughly 1000 and $500 \mathrm{~nm}$, for the samples anodized in aqueous and glycerol/ water electrolytes, respectively. Other authors also observed the presence of nanosheets after zinc anodization in different electrolytes ${ }^{37,38}$ and they attribute this morphology to the quick and fast dissolution of $\mathrm{ZnO}$ in water. Besides, if the zinc electrode is stirred at $2000 \mathrm{rpm}$ during anodization, keeping the rest of the anodization parameters constant, an entirely different morphology is formed, i.e. nanotubes are grown beneath a smoother surface. This might be explained due to the fact that for low $\mathrm{Na}_{2} \mathrm{~S}$ concentrations, stirring may facilitate the growth of $\mathrm{ZnS}$ initiation layer that is essential for the formation of the nanotubes. This effect was previously observed in the anodization of titania nanotubes where fluoride content was limiting the nanotubular structure formation. ${ }^{39}$ The nanotubes formed in glycerol/water electrolytes are shorter compared to the ones anodized in the aqueous solution (500 $\mathrm{nm}$ in comparison to $1000 \mathrm{~nm}$, Fig. 3c and d). This fact might be related to the glycerol nature of the electrolyte. That is, due to its higher viscosity, all the transport processes in this electrolyte are slowed down. ${ }^{\mathbf{4 0}}$ Besides, nanostructures anodized in glycerol electrolytes resemble more a sponge rather than a nanotube. That is, a connected nanoporous network, that resembles a sponge. ${ }^{\mathbf{1 8 , 4 1}}$ This morphology might increase the surface area relation of the nanostructure and additionally possesses a connected pathway for the electron transport.

Fig. S2 and $\mathrm{S} 4 \dagger$ presents the morphology of the $\mathrm{ZnO} / \mathrm{ZnS}$ nanostructures anodized in electrolytes containing $\mathrm{Na}_{2} \mathrm{~S} \quad 0.2$ M. In aqueous electrolytes (Fig. 3e-h), the heterostructures grown in all cases, in the form of nanotubes, regardless the flowing conditions. This is related to the higher sulfide content in the electrolyte, which leads to the formation of the $\mathrm{ZnS}$ initiation layer and then, nanotubes might be formed underneath. Attending to Fig. 3e and g, the length of the nanotubes is in the range of $800-1000 \mathrm{~nm}$. Fig. $\mathrm{S} 4 \dagger$ shows the $\mathrm{ZnO} / \mathrm{ZnS}$ nanostructures anodized in glycerol/water electrolytes. Contrary to this, under these conditions, it can be indicated that hydrodynamic conditions are determinant in the obtained morphology. In fact, under stagnant conditions an hybrid morphology between nanosheets and nanotubes (Fig. 3f) is observed. Nevertheless, when rotating the zinc electrode at 2000 rpm during anodization, the formation of a mixture between nanosponge and nanotubes with $1000 \mathrm{~nm}$ in thickness is obtained (Fig. $3 \mathrm{~g}$ and $\mathrm{h}$ ). This may be attributed to the intrinsic characteristics of the glycerol electrolyte. On the one hand, the higher viscosity under static conditions could delay the nanosponge/nanotubes formation but, on the other hand, the hydrodynamic conditions might help the sulfides and fluorides 
to diffuse through the electrolyte and consequently the ordered tubes are formed.

Additionally, likewise it occurred for the samples anodized in the solutions containing $\mathrm{Na}_{2} \mathrm{~S} 0.06 \mathrm{M}$, hydrodynamic conditions make the surface of the nanostructures more homogeneous and smoother, especially for the nanostructures anodized in glycerol/water media (Fig. S4d $\dagger$ ).

\subsection{Current density transients during anodization}

Fig. 4 shows the current density transients during anodization of zinc at 0 and $2000 \mathrm{rpm}$ in the different electrolytes. When samples were anodized in water electrolytes (Fig. 4a) the current density transients show a sharp decrease in the early stage of anodization, indicating the formation of a $\mathrm{ZnS}$ layer on the zinc surface. For heterostructures anodized in $0.2 \mathrm{M} \mathrm{Na}_{2} \mathrm{~S}$ electrolytes and at $2000 \mathrm{rpm}$ in $0.06 \mathrm{M} \mathrm{Na}_{2} \mathrm{~S}$ electrolytes, after a certain time, the current density rises slowly and decreases again, due to the formation of the nanotubes. For these conditions, FESEM images (Fig. 3c, e and g) reveal the formation of $\mathrm{ZnO} / \mathrm{ZnS}$ nanotubes. The trend of the current density is in agreement with the $\mathrm{TiO}_{2}$ nanotubes formation by Ti anodization. ${ }^{42,43}$ For the heterostructures anodized at $0 \mathrm{rpm}$ and in electrolytes containing $\mathrm{Na}_{2} \mathrm{~S} 0.06 \mathrm{M}$, current density decreases from the initial time until the end of the test, that is, there is a dissolution of the zinc surface and a subsequent formation of nanosheets. The trend of the current density (i.e. a sharp decrease and then it stabilizes) was also observed by other authors that obtained nanosheets from zinc anodization. ${ }^{44}$ Additionally, the registers of the current density corresponding to the nanostructures anodized in the $0.2 \mathrm{M} \mathrm{Na}_{2} \mathrm{~S}$ electrolytes, present the rise of the current density (after its initial sharp decrease) earlier when anodization was performed under stirring the zinc electrode. This might indicate that flowing conditions facilitate nanotubes formation.

According to Fig. $4 \mathrm{~b}$, the current density transients of the nanostructures synthesized in glycerol/water media present a general trend of decreasing at the beginning of the test, and then they reach an equilibrium state. The most remarkable fact of these registers is the low current density values obtained during anodization in electrolytes containing glycerol. This is owing to the fact that electric current densities decrease as water content decreases. ${ }^{45}$ These results are in agreement with other studies that also found that the anodization process slows down in the presence of glycerol, due to its higher viscosity. ${ }^{40}$

In general, some noise signals appear in the current transients of Fig. 4, especially working at static conditions. These signals are related to the formation of bubbles during anodization of zinc that were not removed in stagnant conditions.

\subsection{Photoelectrochemical water splitting measurements}

The $\mathrm{ZnO} / \mathrm{ZnS}$ nanostructures were evaluated as photoanodes in different solutions. It was found that either $\mathrm{KOH}$ or $\mathrm{Na}_{2} \mathrm{SO}_{4}$ solutions were not appropriate for $\mathrm{ZnO} / \mathrm{ZnS}$ photoelectrochemical water splitting characterization. Fig. 5 shows, as an example, the evolution of the photocurrent $v s$. potential of one of the anodized heterostructures in $1 \mathrm{M} \mathrm{KOH}$ (Fig. 5a) and in 0.1
$\mathrm{M} \mathrm{Na}_{2} \mathrm{SO}_{4}$ (Fig. 5b). Fig. 5a shows that in $\mathrm{KOH}$ solutions, the photocurrent density of the nanostructure increases (dissolution of the surface) and then decreases continuously (layer formation). Besides, no photocurrent pulses were observed when sunlight was irradiated on the surface of the sample. This is due to the presence of $\mathrm{OH}^{-}$ions that promotes the formation of a precipitate on the surface of the nanostructures that hinders their proper irradiation and, consequently, the water splitting mechanism. On the other hand, heterostructures evaluated in $\mathrm{Na}_{2} \mathrm{SO}_{4}$ solutions undergo photocorrosion, even working with low concentrations (see Fig. $5 \mathrm{~b}$ ). This might be related to the mild acidic $\mathrm{Na}_{2} \mathrm{SO}_{4}$ nature since anodic zinc oxide is very easily dissolved in acidic conditions. ${ }^{37,46}$

In this way, it was decided to study the photoelectrochemical water splitting of the heterostructures in a sacrificial polysulfide electrolyte, in order to prevent their photocorrosion. ${ }^{17}$ That is, $\mathrm{Na}_{2} \mathrm{~S}$ in the solution acts as a hole scavenger: $\mathrm{S}_{2}{ }^{2-}$ ions, which come from $\mathrm{Na}_{2} \mathrm{~S}$, can react with two holes to form $\mathrm{S}_{2}{ }^{2-}$. The aqueous $\mathrm{SO}_{3}{ }^{2-}$ ions added to the electrolyte act as hole scavenger as well as preventing a back reaction by reducing $\mathrm{S}_{2}{ }^{2-}$ to $\mathrm{S}^{2-}$, and they can react with $\mathrm{S}^{2-}$ to generate $\mathrm{S}_{2} \mathrm{O}_{3}{ }^{2-}$ in order to prevent any sulfur deposition (eqn (2)-(5)). According to this, the photogenerated holes oxidize $\mathrm{Na}_{2} \mathrm{~S}$ and $\mathrm{Na}_{2} \mathrm{SO}_{3}$ instead of water, improving the photocatalytic response of the nanostructures. ${ }^{47,48}$

$$
\begin{gathered}
\mathrm{ZnO} / \mathrm{ZnS}+h \nu \rightarrow \mathrm{h}^{+}+\mathrm{e}^{-} \\
2 \mathrm{~S}^{2-}+2 \mathrm{~h}^{+} \rightarrow \mathrm{S}_{2}{ }^{2-} \\
\mathrm{S}_{2}{ }^{2-}+\mathrm{SO}_{3}{ }^{2-} \rightarrow \mathrm{S}_{2} \mathrm{O}_{3}{ }^{2-}+\mathrm{S}^{2-} \\
\mathrm{SO}_{3}{ }^{2-}+\mathrm{S}^{2-}+2 \mathrm{~h}^{+} \rightarrow \mathrm{S}_{2} \mathrm{O}_{3}{ }^{2-}
\end{gathered}
$$

Besides, Kushwaha ${ }^{6}$ observed that ZnS, with an $1.3 \mathrm{eV}$ higher conduction band position than the $\mathrm{ZnO}$, induced faster electron transfer to the conduction band in photoelectrochemical water splitting tests of $\mathrm{ZnO} / \mathrm{ZnS}$ heterostructures. ${ }^{7,49}$ Therefore, it may be an easy flow of photogenerated electrons towards $\mathrm{ZnO}$ and holes towards the electrolyte via $\mathrm{ZnS}$ and this faster photo charge collection results in improved water splitting performance.

Fig. 6 shows the photoelectrochemical water splitting performance under simulated sunlight $\mathrm{AM} 1.5$ conditions for the different nanostructures in the $\mathrm{Na}_{2} \mathrm{~S} / \mathrm{Na}_{2} \mathrm{SO}_{3}$ solution. It can be observed in terms of the photocurrent transient $v s$. potential curves that the nanostructures obtained under hydrodynamic conditions, and the one anodized at $0 \mathrm{rpm}$ in water electrolytes containing $0.2 \mathrm{M} \mathrm{Na}_{2} \mathrm{~S}$, present a higher performance. This means that electrochemical degradation of the electrode (higher photocurrent densities) did not occur. The nanostructure is stable under dark conditions and its photocurrent densities increase when they were irradiated by the solar light. If the photocurrent response of the mentioned samples is compared with their FE-SEM images (Fig. 3c-e, g and h), it can be observed that the best photoelectrochemical water splitting response is directly related to the nanotubular/nanosponge morphology, 
a)

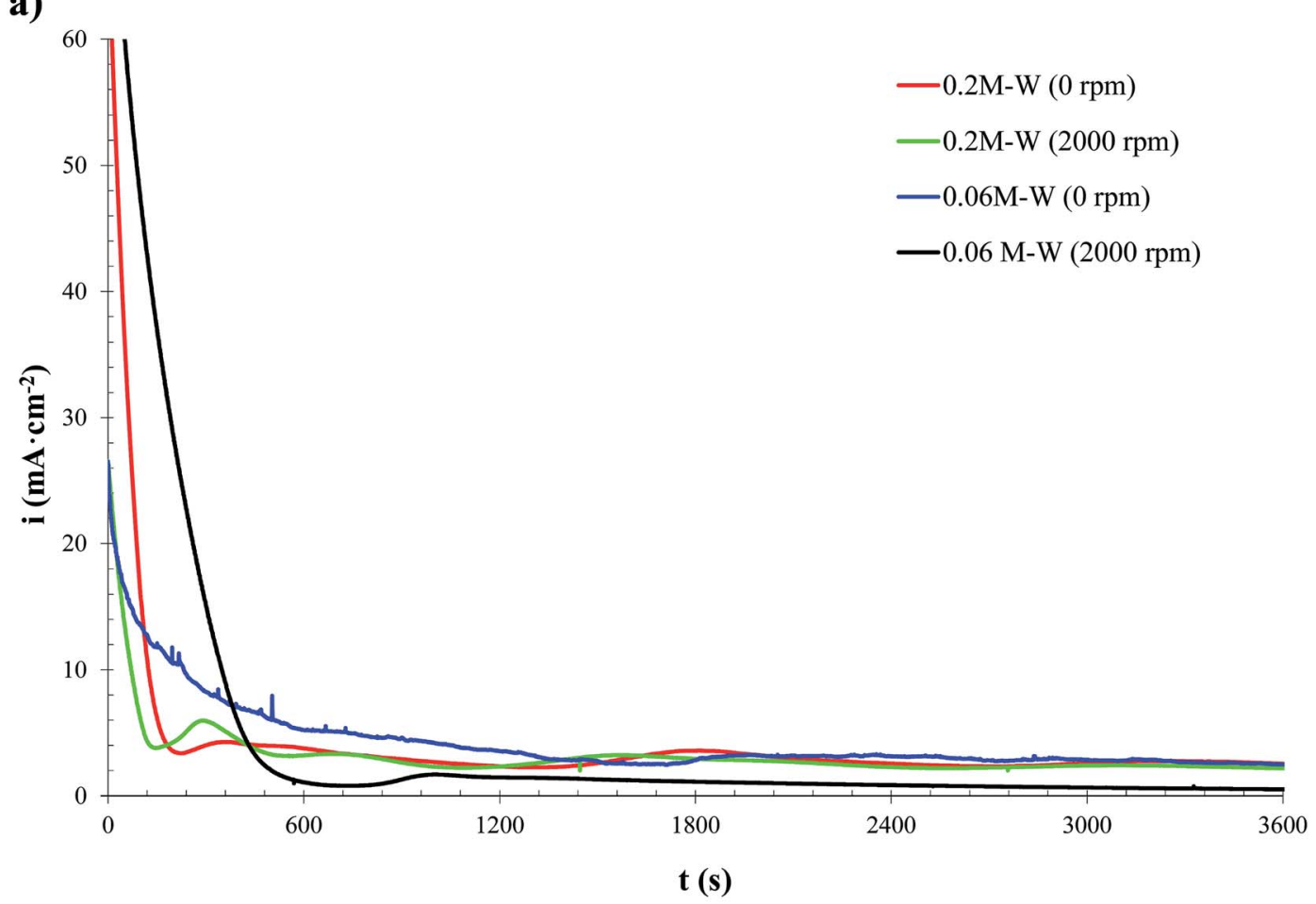

b)

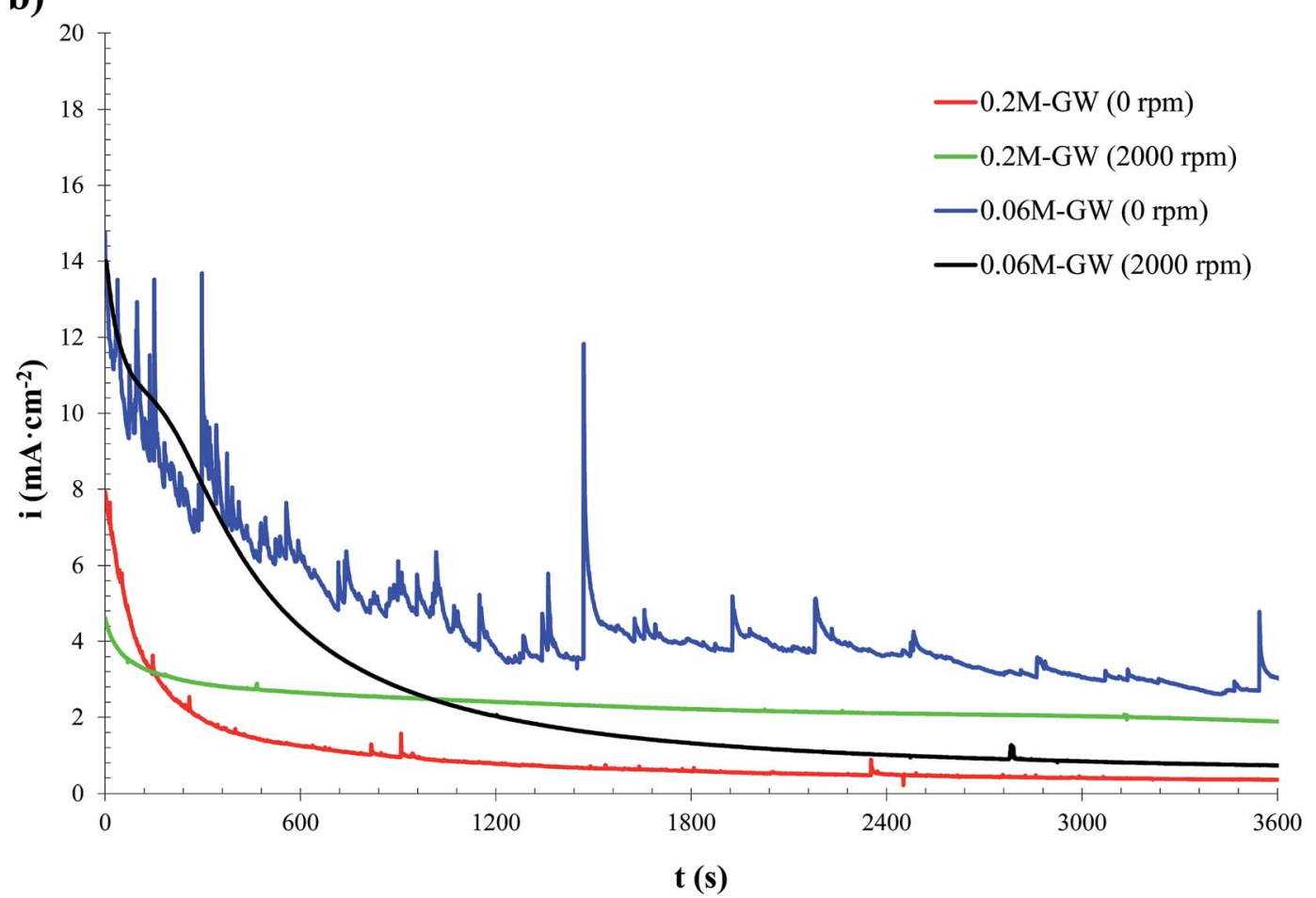

Fig. 4 Current density transient recorded during anodization for all the samples anodized in water: W (a) and glycerol/water: GW (b) electrolytes.

which in the majority of the cases is promoted by stirring the electrolyte during anodization. In addition, the intrinsic high viscosity of glycerol improves the stability of the dark photocurrents obtained for the heterostructures anodized in these electrolytes (Fig. 6b). In those cases, dark photocurrents are close to zero. Besides, Fig. 6 also shows that the photocurrent is potential dependent, since it increases as the applied potential is scanned towards more positive values. In general, the photocurrent densities of the heterostructures are higher than the ones obtained in previous studies ${ }^{50}$ or of the same magnitude order of $\mathrm{ZnO} / \mathrm{ZnS}$ nanostructures synthesized on fluorine-doped tin oxide. $^{6,51}$ All these works produced the heterostructures by 
a)

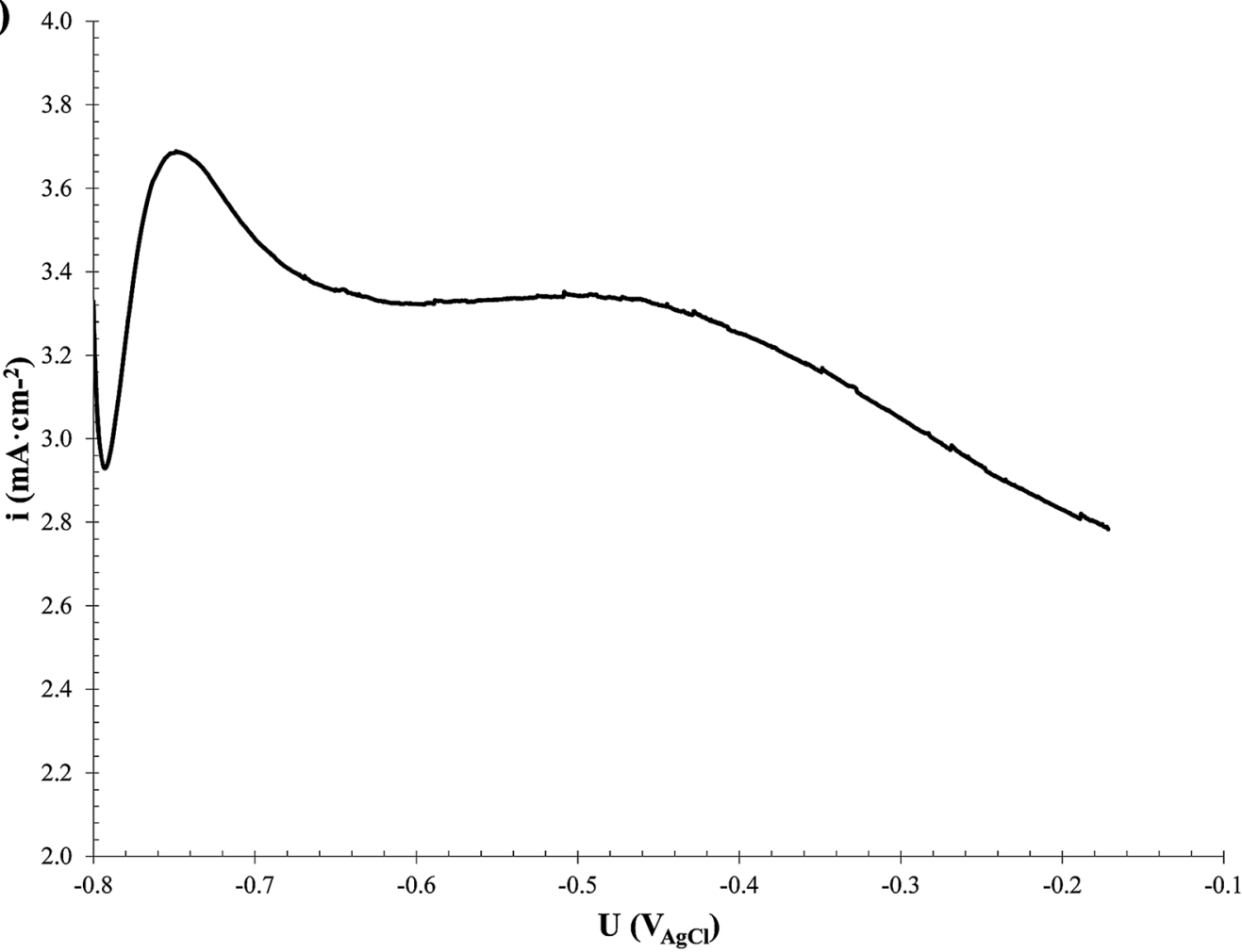

b)

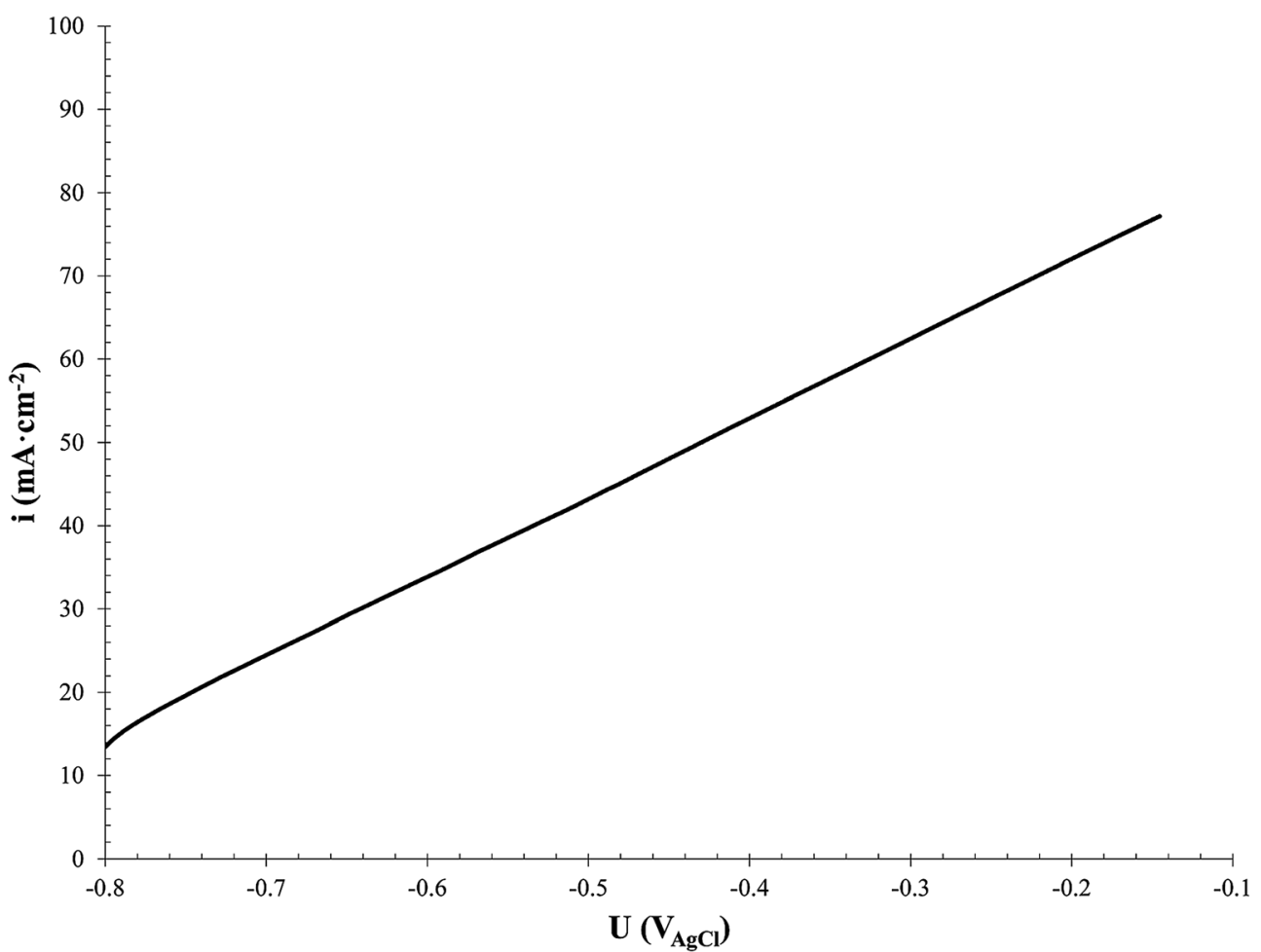

Fig. 5 Photocurrent density transients of the $\mathrm{ZnO} / \mathrm{ZnS}$ nanostructures anodized at $2000 \mathrm{rpm}$ in $0.2 \mathrm{M} \mathrm{Na}_{2} \mathrm{~S}+0.025 \mathrm{M} \mathrm{NH}_{4} \mathrm{~F}$ aqueous solutions measured in $1 \mathrm{M} \mathrm{KOH}$ (a) and in $0.1 \mathrm{M} \mathrm{Na}_{2} \mathrm{SO}_{4}$ (b) under AM 1.5 illumination, as a function of the applied potential.

chemical methods which involve several and, in some cases, straightforward steps. In contrast, with the electrochemical anodization technique used in this study, the heterostructures are directly grown on the metal substrate (back contact), they can be used directly as photoanodes, thus avoiding compaction or sintering of the nanoparticles on the metallic substrate. 


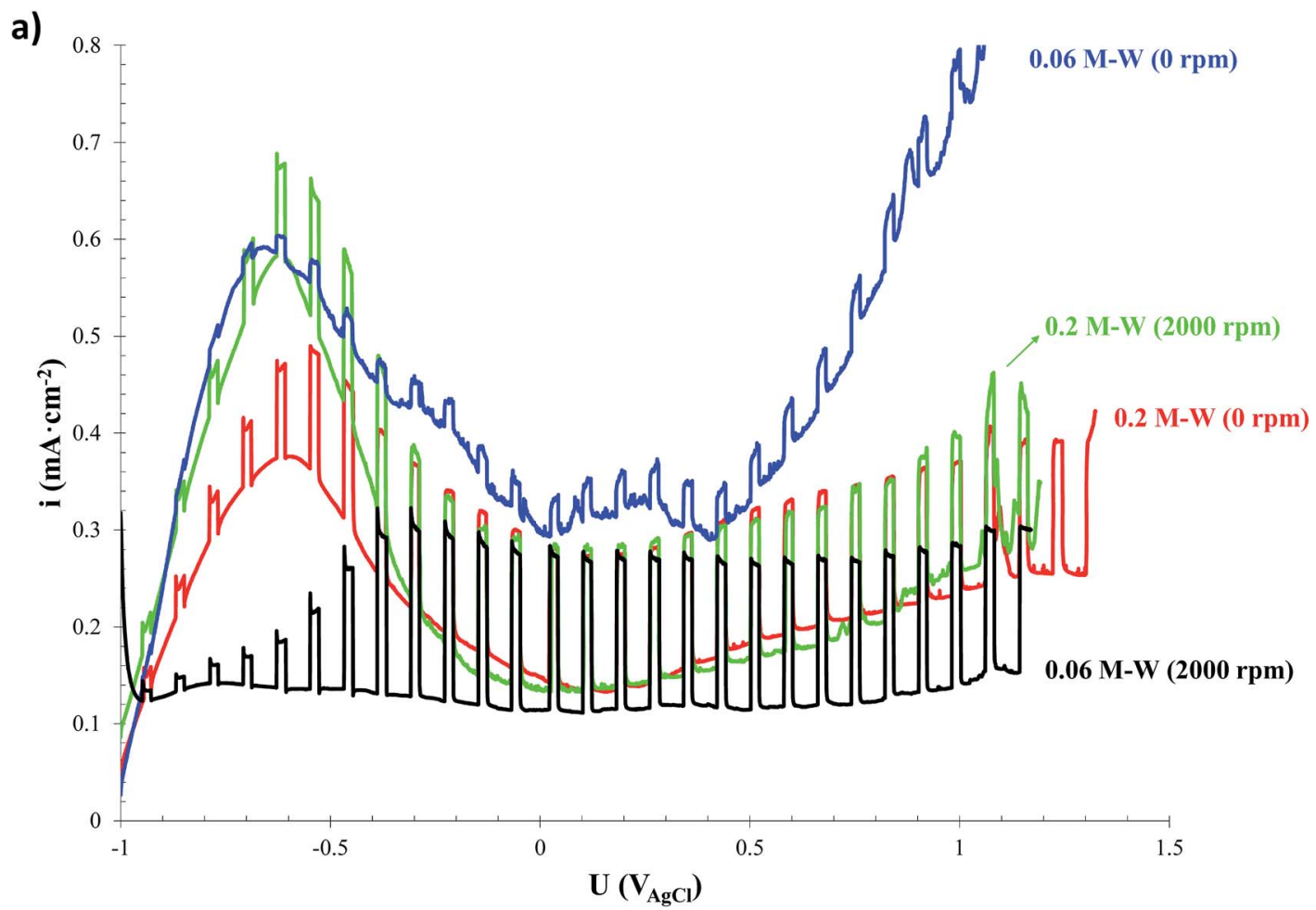

b)

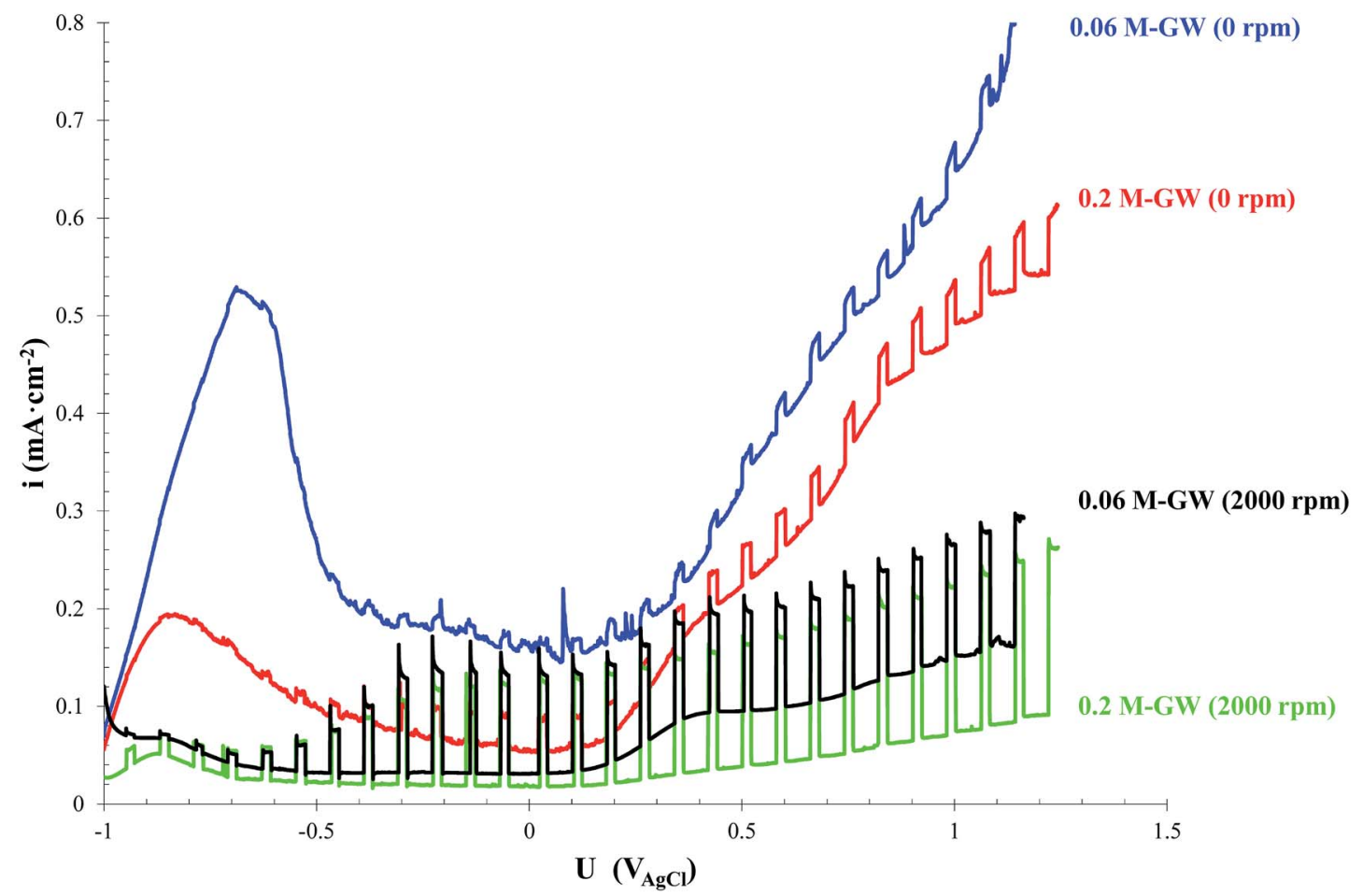

Fig. 6 Photocurrent density transients of the different $\mathrm{ZnO} / \mathrm{ZnS}$ nanostructures anodized in aqueous (a) and glycerol/water (b) electrolytes measured in a $0.24 \mathrm{M} \mathrm{Na}_{2} \mathrm{~S}$ and $0.35 \mathrm{M} \mathrm{Na}_{2} \mathrm{SO}_{3}$ solution under AM 1.5 illumination, as a function of the applied potential.

From all the evaluated samples, the best results are found for the heterostructures anodized if stirring the electrode at 2000 $\mathrm{rpm}$ in glycerol/water electrolytes containing the highest $\mathrm{Na}_{2} \mathrm{~S}$ content $(0.2 \mathrm{M})$, owing to the higher increase of the photocurrent densities obtained under illumination (even at $1.2 \mathrm{~V}_{\mathrm{Ag} / \mathrm{AgCl}}$ ) and the low photocurrents in dark conditions. Therefore, it is 
proved the beneficial effect of the nanotubular/nanosponge morphology together with the stability of the dark photocurrents provided by glycerol.

Fig. S5 $\uparrow$ shows as an example, the photostability in $0.24 \mathrm{M}$ $\mathrm{Na}_{2} \mathrm{~S}$ and $0.35 \mathrm{M} \mathrm{Na}_{2} \mathrm{SO}_{3}$ solution during 1 hour of the heterostructure anodized in $0.2 \mathrm{M} \mathrm{Na}_{2} \mathrm{~S}+0.025 \mathrm{M} \mathrm{NH}_{4} \mathrm{~F}$ glycerol/water solution stirring the electrolyte at $2000 \mathrm{rpm}$, holding at $500 \mathrm{mV}$ the potential under AM 1.5 illumination. From Fig. S5† it can be clearly observed that $\mathrm{ZnS} / \mathrm{ZnO}$ synthesized at higher rotation speeds are stable with time.

\section{Conclusions}

The presence of $\mathrm{ZnO}$ and $\mathrm{ZnS}$ on the nanostructures anodized from zinc is confirmed by Raman spectroscopy and EDX. Raman spectroscopy also showed the presence of photoluminescence occasioned by surface defects which is specially more marked after annealing.

The morphology of the heterostructures was strongly dependent on the electrolyte composition and the hydrodynamic conditions used during anodization. Nanotubes/ nanosponges were obtained under hydrodynamic conditions in all the studied electrolytes.

The viscous nature of glycerol slows down the anodization process and improves the photostability of the nanostructures.

The heterostructures succeed as photococatalyst for photoelectrochemical water splitting in polysulfide aqueous solutions. The best results were obtained for the nanostructures anodized under stirring conditions and in glycerol/water electrolytes.

\section{Acknowledgements}

The authors would like to express their gratitude for the financial support to the Ministerio de Economía y Competitividad (CTQ2013-42494-R), for its help in the Laser Raman Microscope acquisition (UPOV08-3E-012), and for the cofinance by the European Social Fund.

\section{References}

1 K. Maeda and K. Domen, Photocatalytic Water Splitting: Recent Progress and Future Challenges, J. Phys. Chem. Lett., 2010, 1, 2655-2661.

2 J. M. Macak, M. Zlamal, J. Krysa and P. Schmuki, SelfOrganized $\mathrm{TiO}_{2}$ Nanotube Layers as Highly Efficient Photocatalysts, Small, 2007, 3, 300-304.

3 A. Fujishima, X. Zhang and D. Tryk, $\mathrm{TiO}_{2}$ Photocatalysis and Related Surface Phenomena, Surf. Sci. Rep., 2008, 63, 515582.

4 S. S. Shinde, C. H. Bhosale and K. Y. Rajpure, Photoelectrochemical Properties of Highly Mobilized Li-Doped ZnO Thin Films, J. Photochem. Photobiol., B, 2013, 120, 1-9.

5 M. Quintana, T. Edvinsson, A. Hagfeldt and G. Boschloo, Comparison of Dye-Sensitized $\mathrm{ZnO}$ and $\mathrm{TiO}_{2}$ Solar Cells: Studies of Charge Transport and Carrier Lifetime, J. Phys. Chem. C, 2007, 111, 1035-1041.
6 A. Kushwaha and M. Aslam, ZnS Shielded ZnO Nanowire Photoanodes for Efficient Water Splitting, Electrochim. Acta, 2014, 130, 222-231.

7 R. Zamiri, D. M. Tobaldi, H. A. Ahangar, A. Rebelo, M. P. Seabra, M. S. Belsley and J. M. F. Ferreira, Study of Far Infrared Optical Properties And Photocatalytic Activity of $\mathrm{ZnO} / \mathrm{ZnS}$ Hetero-Nanocomposite Structure, RSC Adv., 2014, 4, 35383-35389.

8 W. Jia, B. Jia, F. Qu and X. Wu, Towards a Highly Efficient Simulated Sunlight Driven Photocatalyst: A Case of Heterostructured $\mathrm{ZnO} / \mathrm{ZnS}$ Hybrid Structure, Dalton Trans., 2013, 42, 14178-14187.

9 X. Wu, P. Jiang, Y. Ding, W. Cai, S. Xie and Z. L. Wang, Mismatch Strain Induced Formation of $\mathrm{ZnO} / \mathrm{ZnS}$ Heterostructured Rings, Adv. Mater., 2007, 19, 2319-2323.

10 L. Zheng, Y. Zheng, C. Chen, Y. Zhan, X. Lin, Q. Zheng, K. Wei and J. Zhu, Network Structured $\mathrm{SnO}_{2} / \mathrm{ZnO}$ Heterojunction Nanocatalyst with High Photocatalytic Activity, Inorg. Chem., 2009, 48, 1819-1825.

11 Z. Wang, B. Huang, Y. Dai, X. Qin, X. Zhang, P. Wang, H. Liu and J. Yu, Highly Photocatalytic $\mathrm{ZnO} / \mathrm{In}_{2} \mathrm{O}_{3}$ Heteronanostructures Synthesized by a Coprecipitation Method, J. Phys. Chem. C, 2009, 113, 4612-4617.

$12 \mathrm{~S}$. Balachandran and M. Swaminathan, The Simple, Template Free Synthesis of a $\mathrm{Bi}_{2} \mathrm{~S}_{3}-\mathrm{ZnO}$ Heterostructure and Its Superior Photocatalytic Activity under UV-A Light, Dalton Trans., 2013, 42, 5338-5347.

13 J. Han, Z. Liu, K. Guo, B. Wang, X. Zhang and T. Hong, Applied Catalysis B: Environmental High-Efficiency Photoelectrochemical Electrodes Based on $\mathrm{ZnIn}_{2} \mathrm{~S}_{4}$ Sensitized ZnO Nanotube Arrays, Appl. Catal., B, 2015, 163, 179-188.

14 A. Kudo and Y. Miseki, Heterogeneous Photocatalyst Materials for Water Splitting, Chem. Soc. Rev., 2009, 38, 253-278.

15 J. Yan, X. Fang, L. Zhang, Y. Bando, U. K. Gautam, B. Dierre, T. Sekiguchi and D. Golberg, Structure and Cathodoluminescence of Individual $\mathrm{ZnS} / \mathrm{ZnO}$ Biaxial Nanobelt Heterostructures, Nano Lett., 2008, 8, 2794-2799.

16 R. Sánchez-Tovar, R. M. Fernández-Domene, D. M. GarcíaGarcía and J. García-Antón, Enhancement of Photoelectrochemical Activity for Water Splitting by Controlling Hydrodynamic Conditions on Titanium Anodization, J. Power Sources, 2015, 286, 224-231.

17 N. K. Shrestha, K. Lee, R. Hahn and P. Schmuki, Electrochemistry Communications Anodic Growth of Hierarchically Structured Nanotubular ZnO Architectures on Zinc Surfaces Using a Sulfide Based Electrolyte, Electrochem. Commun., 2013, 34, 9-13.

18 R. Sánchez-Tovar, K. Lee, J. García-Antón and P. Schmuki, Formation of Anodic $\mathrm{TiO}_{2}$ Nanotube or Nanosponge Morphology Determined by the Electrolyte Hydrodynamic Conditions, Electrochem. Commun., 2013, 26, 1-4.

19 R. Cuscó, E. Alarcón-Lladó, J. Ibáñez, L. Artús, J. Jiménez, B. Wang and M. J. Callahan, Temperature Dependence of Raman Scattering in ZnO, Phys. Rev. B: Condens. Matter Mater. Phys., 2007, 75, 165202-165212. 
20 M. Rajalakshmi, A. K. Arora, B. S. Bendre and S. Mahamuni, Optical Phonon Confinement in Zinc Oxide Nanoparticles, $J$. Appl. Phys., 2000, 87, 2445-2448.

21 A. Kaschner, U. Haboeck, M. Strassburg, M. Strassburg, G. Kaczmarczyk, A. Hoffmann, C. Thomsen, A. Zeuner, H. R. Alves, D. M. Hofmann, et al., Nitrogen-Related Local Vibrational Modes in ZnO: N, Appl. Phys. Lett., 2002, 80, 1909-1911.

22 Ü. Özgür, Y. I. Alivov, C. Liu, A. Teke, M. A. Reshchikov, S. Doğan, V. Avrutin, S. J. Cho and H. Morkọ, A Comprehensive Review of $\mathrm{ZnO}$ Materials and Devices, $J$. Appl. Phys., 2005, 98, 1-103.

23 S. He, M. Zheng, L. Yao, X. Yuan, M. Li, L. Ma and W. Shen, Preparation and Properties of ZnO Nanostructures by Electrochemical Anodization Method, Appl. Surf. Sci., 2010, 256, 2557-2562.

24 Y. C. Cheng, C. Q. Jin, F. Gao, X. L. Wu, W. Zhong, S. H. Li and P. K. Chu, Raman Scattering Study of Zinc Blende and Wurtzite ZnS, J. Appl. Phys., 2009, 106, 123505-123509.

25 S. M. Scholz, R. Vacassy, L. Lemaire, J. Dutta and H. Hofmann, Nanoporous Aggregates of $\mathrm{ZnS}$ Nanocrystallites, Appl. Organomet. Chem., 1998, 12, 327-335.

26 E. Mendelovici, R. L. Frost and T. Kloprogge, Cryogenic Raman Spectroscopy of Glycerol, J. Raman Spectrosc., 2000, 31, 1121-1126.

27 A. Mudalige and J. E. Pemberton, Raman Spectroscopy of glycerol/D2O Solutions, Vib. Spectrosc., 2007, 45, 27-35.

28 A. Kushwaha, H. Tyagi and M. Aslam, Role of Defect States in Magnetic and Electrical Properties of ZnO Nanowires, AIP Adv., 2013, 3, 042110-042115.

29 S. Chang, S. Ok, H. Jeong and A. Sakai, Luminescence Properties of Zn Nanowires Prepared by Electrochemical Etching, Mater. Lett., 2002, 53, 432-436.

30 Y. Z. Zhang, L. H. Wu, Y. P. Liu and E. Q. Xie, Improvements to the Hierarchically Structured ZnO Nanosphere Based DyeSensitized Solar Cells, J. Phys. D: Appl. Phys., 2009, 42, 085105-085110.

31 X. F. Wu, G. W. Lu, C. Li and G. Q. Shi, Room-Temperature Fabrication of Highly Oriented ZnO Nanoneedle Arrays by Anodization of Zinc Foil, Nanotechnology, 2006, 17, 49364940.

32 C. Ye, X. Fang, G. Li and L. Zhang, Origin of the Green Photoluminescence from Zinc Sulfide Nanobelts, Appl. Phys. Lett., 2004, 85, 3035-3037.

33 X. Zhang, Y. Zhang, Y. Song, Z. Wang and D. Yu, Optical Properties of ZnS Nanowires Synthesized via Simple Physical Evaporation, Phys. E, 2005, 28, 1-6.

34 J. H. Kim, H. Rho, J. Kim, Y. Choi and J. Park, Raman Spectroscopy of ZnS Nanostructures, J. Raman Spectrosc., 2012, 7, 906-910.

35 Y. Zhang, Y. Liu, L. Wu, H. Li, L. Han, B. Wang and E. Xie, Effect of Annealing Atmosphere on the Photoluminescence of ZnO Nanospheres, Appl. Surf. Sci., 2009, 255, 4801-4805.

36 R. Thurn and W. Kiefer, Structural Resonances Observed in the Raman Spectra of Optically Levitated Liquid Droplets, Appl. Opt., 1985, 24, 1515-1519.
37 S. J. Kim and J. Choi, Self-Assembled Arrays of ZnO Stripes by Anodization, Electrochem. Commun., 2008, 10, 175-179.

38 J. Zhao, X. Wang, J. Liu, Y. Meng, X. Xu and C. Tang, Controllable Growth of Zinc Oxide Nanosheets and Sunflower Structures by Anodization Method, Mater. Chem. Phys., 2011, 126, 555-559.

39 R. Sánchez-Tovar, I. Paramasivam, K. Lee and P. Schmuki, Influence of Hydrodynamic Conditions on Growth and Geometry of Anodic $\mathrm{TiO}_{2}$ Nanotubes and Their Use towards Optimized DSSCs, J. Mater. Chem., 2012, 22, 12792-12795.

40 M. Stępień, P. Handzlik and K. Fitzner, Synthesis of $\mathrm{ZrO}_{2}$ Nanotubes in Inorganic and Organic Electrolytes by Anodic Oxidation of Zirconium, J. Solid State Electrochem., 2014, 18, 3081-3090.

41 R. Sanchez-Tovar, K. Lee, J. Garcia-Anton and P. Schmuki, Photoelectrochemical Properties of Anodic $\mathrm{TiO}_{2}$ Nanosponge Layers, ECS Electrochem. Lett., 2013, 2, H9-H11.

42 P. Roy, S. Berger and P. Schmuki, $\mathrm{TiO}_{2}$ Nanotubes: Synthesis and Applications, Angew. Chem., Int. Ed., 2011, 50, 29042939.

43 A. Ghicov and P. Schmuki, Self-Ordering Electrochemistry: A Review on Growth and Functionality of $\mathrm{TiO}_{2}$ Nanotubes and Other Self-Aligned MOx Structures, Chem. Commun., 2009, 2791-2808.

44 J. Zhao, X. Wang, J. Liu, Y. Meng, X. Xu and C. Tang, Controllable Growth of Zinc Oxide Nanosheets and Sunflower Structures by Anodization Method, Mater. Chem. Phys., 2011, 126, 555-559.

45 A. Valota, D. J. LeClere, P. Skeldon, M. Curioni, T. Hashimoto, S. Berger, J. Kunze, P. Schmuki and G. E. Thompson, Influence of Water Content on Nanotubular Anodic Titania Formed in Fluoride/glycerol Electrolytes, Electrochim. Acta, 2009, 54, 4321-4327.

46 S. J. Kim, J. Lee and J. Choi, Understanding of Anodization of Zinc in an Electrolyte Containing Fluoride Ions, Electrochim. Acta, 2008, 53, 7941-7945.

47 L. Wei, Y. Chen, J. Zhao and Z. Li, Preparation of NiS/ZnIn ${ }_{2} \mathrm{~S}_{4}$ as a Superior Photocatalyst for Hydrogen Evolution under Visible Light Irradiation, Beilstein J. Nanotechnol., 2013, 4, 949-955.

48 H. Kim, M. Seol, J. Lee and K. Yong, Highly Efficient Photoelectrochemical Hydrogen Generation Using Hierarchical ZnO/WOx Nanowires Cosensitized with CdSe/ CdS, J. Phys. Chem. C, 2011, 115, 25429-25436.

49 W. Liu, R. Wang and N. Wang, From ZnS Nanobelts to ZnO/ ZnS Heterostructures: Microscopy Analysis and Their Tunable Optical Property, Appl. Phys. Lett., 2010, 97, 20082011.

50 H. Zhao, Y. Dong, P. Jiang, X. Wu, R. Wu and Y. Chen, Facile preparation of a $\mathrm{ZnS} / \mathrm{ZnO}$ nanocomposite for robust sunlight photocatalytic $\mathrm{H}_{2}$ evolution from water, RSC Adv., 2015, 5, 6494-6500.

51 P. Guo, J. Jiang, S. Shen and L. Guo, ZnS/ZnO heterojunction as photoelectrode: type II band alignment towards enhanced photoelectrochemical performance, Int. J. Hydrogen Energy, 2013, 38, 13097-13103. 